\title{
Language Ideologies of Young Chinese Surabayanese in Learning Mandarin in Post Suharto Era
}

\author{
Gabriela Angeline Hananya \\ Petra Christian University, INDONESIA \\ e-mail: angelinegabriela@yahoo.com
}

\begin{abstract}
This is the study of language ideologies of young Chinese Surabayanese which influence their decision to learn Mandarin. The approach of this study is qualitative, and the data are gathered through semi-structured interviews and participant observation. There are four young Chinese Surabayanese participating in this study. The findings show that young Chinese Surabayanese, as reflected in the case of the informants in this study, perceive that learning Mandarin is advantageous for their job prospect. Their belief that learning Mandarin may give them advantages is due to four factors, namely, globalizing life opportunities in working and communication, the rise of China, linguistic capital investment, and parental influence. Thus, their ideologies in learning Mandarin mainly focus on the benefits and advantages that they believe they may get by learning the language.
\end{abstract}

Keywords: Language ideology; Mandarin learning; young Chinese Surabayanese.

\section{INTRODUCTION}

Historical records show that the Chinese have been in Surabaya since before the sixteenth century (Salmon, 2009). They experienced a cultural decline due to the strong assimilation into the local community until around the nineteenth century. The Chinese in Surabaya (henceforth, Chinese Surabayanese) rarely experience "abuse and violence." Nevertheless, both of them still have some impacts on their lives, especially during the New Order era, in which Chinese Indonesians experienced massive discrimination (Suprajitno, 2019). When the New Order was in power, there were no public displays of Chinese language and culture. Chinese language or Mandarin was restricted for the sake of national language ideology. This ideology was deemed necessary by the state for assimilating the Chinese into Indonesian nationhood.

Eventually, with little to no access to practicing Chinese language and Chinese culture because of by the regime's oppressive policies, "Chinese Indonesians were practically stripped of their heritage language, and those who were born and raised during this time and their subsequent counterparts do not speak the language" (Kurniawan \& Suprajitno, 2019, p. 1). The regime's policies toward the Chinese in Indonesia might reflect "the popular view of Chinese Indonesians as essentially foreigners within the framework of
Indonesia's ethno-nationalist ideology" (Setijadi, 2015, p. 144). Therefore, learning Mandarin in Indonesia implied the idea of being an alien to the country, especially supposing that one spoke Mandarin better than Indonesian. However, the fall of the New Order regime in 1998 ushered a new era of reform, locally known as Reformasi (The Reform) era, characterized by drastic changes. One important change was the change that "dealt with policies concerning the ethnic Chinese. It allowed Chinese Indonesians to regain a space in public life after more than thirty years of being marginalized and discriminated against"'(Suprajitno, 2019, p. 333). Therefore, young generation of Chinese Indonesians are now free to express their cultural identity, to pursue their dream to learn Mandarin in the public sphere. Many decided to coin this event as a return to their Chinese identity, popularly known as "resinification," that is "the revival of hitherto devalued, occluded, or repressed 'Chineseness,' and more generally to the phenomenon of increasing visibility, acceptability, and selfassertiveness of ethnic Chinese in Southeast Asia and elsewhere (Hau, 2012, p. 1). However, when an individual of Chinese descent decides to learn Mandarin, however, the individual may not intend to claim their claim their Chinese roots back. In their study, Kurniawan and Suprajitno (2019) find that Chinese Indonesians who learn Mandarin are motivated by the perceived benefit the mastery of Mandarin offers, not by the intention to explore their cultural identity. 
Wen (2011) writes that there are a number of studies on language learning motivation that focus on Mandarin and other languages. However, there are a few studies discussing the motivation and the ideologies of young Chinese Surabayanese on learning Mandarin. That is why in this paper, I examine the motivation and language ideologies of this group of people. Since all of my young Chinese Surabayanese informants were introduced to Mandarin through their parents, I explore how the ideologies within young Mandarin learners of Chinese Surabayanese push them to learn the language.

\section{THEORETICAL FRAMEWORK}

This study is informed by Woolard's (1998) idea of language ideology, also knowns as linguistic ideology. In Woolard's opinion, language ideology refers to "representations, whether explicit or implicit, that construe the intersection of language and human beings in a social world" (1998, p. 3). Simply put, language ideology is a discussion about a set of beliefs within a language and involves interaction in between the two (Zhou, 2019, p. 35). This interaction results in influencing the speakers' worldview and their personal beliefs unconsciously (Bewley, 2018), thus creating a language that is socially approved in people's mind. Bewley (2018) also emphasizes that speakers of a language might not realize that there is a set of beliefs in their language that influences their worldview, because the set of beliefs is naturalized in their daily lives. Nevertheless, "the value and importance of language" may change, depending on the dynamics of the society, especially in the era of globalization (Hui, 2007, p. 3).

Additionally, in one way or another, interactions among interlocutors change the ideology within a language because language use perpetuates speakers' personal belief. This creates a preferred and socially approved language use in the society. These interlocutors, in turn, use their personal belief knowledge as a basis for evaluating others and ascribing values to their preferred language and accent. The preferred language and accents, then, become the standard language and accent. That is why every approved linguistic token distributed through educational institutions achieves different kinds of economic value within the labor market, which can be viewed as the evidence of the unequal distribution of power and privilege in the society. Since the mastery of this standard language upholds the speakers' educational and economic opportunity, graduates of the highest level of educational institutions with great linguistic competency are viewed by others as possessing desirable social characteristics. This advantage may result in better career prospects in job market. So, people who possess the agreed upon linguistic form would dominate the marketplace they are in.

The notion of the agreed upon linguistic form inspires me in analyzing language learners' motivation and goal in learning a new language. Both their motivation and goal are intertwined to one another. Gardner (1985) classifies motivation in language learning into integrative and instrumental. She explains that when language learners want to identify themselves as a part of the community that speaks the target language, or to blend themselves into that community, then their motivation is called integrative. On the other hand, when the language learners orient their motivation toward "a more functional reason, ... such as getting a good job or passing an examination," then their motivation is called instrumental (Mu, 2016, p. 29). In addition, motivation also speaks about respect in a way that, "the more that a student admires the target culture - reads its literature, visits it on holiday, looks for opportunities to practice the language, and so on - the more successful they will be in the L2 classroom" (Cook, 2008, p. 137-138).

However, Norton views that Gardner's theory is too narrow and does not yet acknowledge the "unequal relations of power between language learners and target language speaker' (2013, p. 6). She proposes the theory of motivation in language learning from a different perspective, that is, the theory of investment was born (Norton, 2013). Norton's idea on the theory of motivation in language learning finds support in Dörnyei \& Ushioda (2009) and Murray, Gao, \& Lamb (2011). According to these scholars, investment is "conceptualized as a sociological complement to the psychological construct of motivation" (Darvin \& Norton, 2015, p. 37).

Norton writes that in performing this motivation of investment, language learners understand the benefit "which will in turn increase the value of their cultural capital and social power" (2013, p. 6). One of the main points of Norton's investment theory is about the acknowledgement of capital in this motivation. The capital that language learners gain is essential for their own identity because it might help define the learners' ability through mastering that language. By understanding the principle in increasing learners' capital through learning a language and putting it into practice, people could accept that the perceived benefit of language learning can increase of language learners' self-esteem and linguistic capital.

To sum up, Norton's theory of investment plays a significant role in the field of language learning. It 
supplements Gardner's theory of motivation. For Norton, motivation is dependent on how language learners use it in their language investment. There are language learners that have instrumental motivation, that is, they are motivated to learn a new language due to the perceived benefits they can get. There are also language learners who have integrative motivation, namely, they learn the language because they want to use it for constructing their identity (Cummins, 2006; $\mathrm{He}, 2006)$.

\section{METHOD}

\section{Participants}

In this study, I selected four young Chinese Surabayanese who currently reside in Surabaya. They are Mandarin language students and teachers in a Mandarin language center (Surabaya International Institute of Business and Technology/SIIBT) in Surabaya. Their ages vary; however, they were all born in 1990-1998. They are two female students, Ella (23 years old) and Lia (21 years old); one female teacher, Amy (24 years old); and one male teacher, Dennis (29 years old). When I conducted this research, all of my informants claimed that they were still in the active process of learning Mandarin through formal or nonformal educational institutions. All of my informants reported the same reason on why they decided to start learning Mandarin, that is, their parents asked them to do so.

\section{Instrument and Procedure}

I used participant observation and in-depth semistructured interviews to collect appropriate data. I used the semi-structured interviews in order that my informants are able to express their opinions, point of views and stories freely. I conducted the interviews occasionally. I interviewed Dennis and Amy once because of their busy work schedule. However, I managed to interview Lia and Ella twice. According to Yin (2011), the semi-structured interviewed method is flexible and adaptive because the conversation flows accordingly, and the informants are free to talk in some depth, choosing their own words.

The questions asked in the interviews were mainly about the informants' motivations in learning Mandarin, how they know Mandarin, their opinions about Mandarin, and factors influencing their motivation to learn Mandarin. The questions for the interviews were semi-structured and comfortably done in Indonesian. The interviews lasted around 30-45 minutes.

\section{FINDINGS AND DISCUSSION}

The result of the interviews shows one major ideology supported by four important factors related to my informants' perspectives in learning Mandarin. In this case, their major ideology is that learning Mandarin is perceived as an advantage. This ideology is supported and well explained by four more detailed supporting factors namely, globalizing life opportunities in the field of communication and work, the rise of China, linguistic capital investment, and lastly, parental influence.

\section{Learning Mandarin Perceived as an Advantage}

Many Indonesians believe in the popular notion that Mandarin is notoriously difficult to learn. It often happens that, despite acknowledging that Mandarin is beneficial, they feels discouraged to learn the language due to its complex grammatical structure, tonal, and writing system. Nevertheless, there are also a number of Indonesians who spare no efforts in learning Mandarin because they believe that the advantages they will get from learning language outweigh the difficulties in learning it. All of my young Chinese Surabayanese informants fall into this category. In their opinion, learning Mandarin has quite a number of advantages in references of present and future use that makes the language is worth learning. They perceive that learning Mandarin is useful for their life. They also believe that learning the language is not waste of time. Their belief is constructed by the aforementioned four factors, which I explain below.

\section{Globalizing Life Opportunities: Communication and Work}

Globalization refers to "the worldwide interconnection of economic and cultural systems" (Lee, 2006, p.9). Although it is strongly associated with trade and economy, such as the growing interrelatedness of local economies across the globe, globalization also has a significant linguistic dimension. Due to their geopolitical factor, certain languages appear to be gaining relative influence, often at the expense of other languages, resulting in a new linguistic hierarchy (Dörnyei, Csizér \& Németh, 2006, p. 7). Language has become increasingly necessary in gaining competitive advantage for the increasing of globalization in trade and business, which "affects the ability of multinational organizations to compete on the global market." (Dhir, 2005, p. 358). The spread of English is surely both a resource for modernization and a source of contention, but interestingly, Mandarin is challenging the global dominance of English, due to its economic success in the global world. 
China's economic success, according to Bianco, "has stimulated phenomenal expansion in the teaching and learning of Chinese" (2007, p. 5). Kurniawan \& Suprajitno notes that "the impact of China's economic growth has created a new atmosphere in learning Chinese (2019, p.1). Mandarin offers "practical value [which] has surpassed that of French, German, and even Japanese in much of the world and its future opportunities seem limitless (Ding \& Saunders, 2006, p. 9).

The factor of globalization, which can be translated as having more opportunities in the field of communication and work, comes to the mind of my informants when they think of learning Mandarin. All of them mention how mastering Mandarin or at least being able to speak a bit of Mandarin would help open up job opportunities. Lia is aware that Mandarin plays an important role in the globalized world of job opportunities these days.

Lia: Yes, if Mandarin is no longer used, I mean [if] Mandarin is getting less and less important in the working field, I will not learn Chinese I think, won't learn Mandarin

Lia is aware that Mandarin plays an important role in the globalized job market these days. She even explicitly mentions that if Mandarin is no longer powerful or important in job market, she will stop learning it. Lia's statement implies that Mandarin can increase its learners' competitiveness. In her opinion, Mandarin is only useful because it can give her more job opportunities, no more than that. If Mandarin is no longer considered as important, she does not need to learn it. Similarly, Ella also shares the same opinion. Ella says how globalization takes place in her father's business, where there are no boundaries from one country to another.

Ella: Now, I think Mandarin is important for working purposes. Because there are many things to do that have something to do with Chinese people. For example, my dad works in factory so if he wants to buy machinery, it must be from China. And so, to keep the maintenance of the machines, [they] usually call technicians from China directly. And if you want to have [business] partners, mostly come from China, so of course I have to learn [Mandarin]. I also think that it could increase my knowledge.

From Ella's point of view, due to her father's line of work, Mandarin means business opportunity. Ella states that learning Mandarin might enable her to gain more knowledge. However, her priority is helping her father in his business. Nevertheless, her answer shows a sense of doubt whether Mandarin would be crucial in her future career or not. The use of the word, 'I think', in her answer, could be interpreted as her having never experienced the importance of Mandarin in her working life directly. Her answer comes from a common knowledge that if an individual masters the second global language, which in this case is Mandarin, it would be great, then.

Additionally, Amy's statement also in line with that of Lia and Ella. Amy takes pride in mastering Mandarin, as seen in her statement below.

Amy: Yes, doors of future, also meeting new people too. So, build more connection, meeting those from same profession [teacher to teacher] ... And, mastering Mandarin has become one [of my] distinct skills, or could be called as one of my talents, which is the only one that I paid attention to, I think.

Amy emphasizes that learning Mandarin not only opens up doors of opportunities but also enables her to have more connection with others in this globalized world. Goh \& Lim supports Amy's opinion in regard to "the shift in economic relations has a profound effect on the popularity and use of a language" (2010, p. 21), where globalization enters and holds the ground. In this sense, Amy's opinion of globalization is different from both Lia and Ella's. If Lia and Ella orient globalization towards working opportunities, Amy leans more toward the idea of communication and making new connections.

Another informant, Dennis, says that without the mastery of Mandarin, he is nearly insignificant to others. Although he seems to exaggerate the importance of Mandarin, Dennis highlights how Mandarin brings a lot of potentials to its learners. He believes that the mastery of Mandarin can open doors to opportunity. Thus, Mandarin means the "language of opportunity" (Goh \& Lim, 2010, p. 20). He sees Mandarin as a bridge that connects worlds of opportunities and communication. Thus, for Dennis, Mandarin facilitates himself to bond with other Mandarin speakers, performing little to no meaningful language barrier in a cultural sense. Therefore, the moment Dennis starts to put his Mandarin skill into use, globalization starts its process.

At this point, all of my young Chinese Surabayanese informants are affected by the push of globalization, the need for communication and competition in the global marketplace that directs them to start learning Mandarin. They believe that being equipped with Mandarin, they can compete in the global marketplace. From their point of view, Mandarin holds a 
promising future in this global world. Learning Mandarin would indeed help to globalize an individual's working opportunities. Nevertheless, Mandarin learners should keep in their minds that, even though Mandarin is now globally known, its impact outside Asia is not so big as they imagine. Nevertheless, many people agree that the mastery of Mandarin is important in some aspects, such as having more working opportunities, establishing new connection with new people, and being the bridge that connects two different culture in this globalized world. Mandarin is now climbing up, second to English, which had tight connection with economy, trade, and opportunities. Therefore, in this case, learning Mandarin is perceived as an advantage in the references of globalizing the learner's communication skill, job vacancies, and life opportunities.

\section{The Rise of China}

In their study, Kurniawan \& Suprajitno notes that "due to the rise of China as a global power, Chinese has become a crucial language to learn across the globe (2019, p. 1). The success of the growth of Chinese economy has brought trust to the world in China's prospects. China's increasing economic power in the world triggers many countries to include Mandarin in their national curriculum. For example, in 2004, Indonesia "formalized Chinese as a second foreign language subject set in curriculum and taught in public schools (Kurniawan \& Suprajitno, 2019, p. 2). China's economic growth leads the proficiency in Mandarin to being an ever-present requirement in finding job. So, learning Mandarin is crucial for graduates who are joining a global marketplace. That is why the rise of China is considered as one important factor to learn Mandarin, as Lia says.

Lia: Obviously, because with the rise of China, we get more opportunities...

Lia states further that because of the rise of China, China offers more opportunities than ever. Lia's statement is in line with Crystal's opinion about global language. Using English as an example, Crystal writes that "any language at the center of such an explosion of international activity would suddenly have found itself with a global status," (in Goh and Lim, 2010, p. 17). The economic growth of China has indeed created a solid and fundamental ground for its language and culture to flourish around the world. When it is said that China's growth would be unlimited, people often think that Mandarin would be the language of the future, particularly when it comes to business, trade, or other economic reasons. Another informant, Ella, also shares similar idea regarding Mandarin and the rise of China. While telling me that the rise of China has nothing to do with her motivation to learn Mandarin, she acknowledges that Mandarin plays a big role in the global world. Her acknowledgement on Mandarin is proven by the fact that the mastery of Mandarin could help her father's business. Amy concurs with Ella. While stating that the rise of China plays no roles in her motivation to learn Mandarin, she agrees that China's increasing economic power makes the country more prosperous than before, albeit its economic disparity, and this results in the increasing number of Mandarin learners who wants to capitalize on the economic power of China.

On the other hand, my oldest informant, Dennis, is aware of how Chinese investors are slowly making their ways to invest in Indonesia. He further states that "although learning Mandarin is difficult and hard, the benefit is amazing." This this statement confirms that he acknowledges the fact of mastering Mandarin gives its speakers an advantage. For example, it helps mandarin speakers to be the bridge between Chinese investors in Indonesia and Indonesian businessmen and workers; it also helps them to find opportunities for their career advancement. While he does not state clearly about it, the rise of China, Dennis understands the impacts of the rise of China on the interest in learning Mandarin.

In brief, the three informants, Ella, Amy, and Dennis, do not stated clearly that the rise of China affects their motivation to learn Mandarin. It is only one informant, Lia, who thinks that the rise of China definitely has an effect on the growing demand of Mandarin in the global marketplace. Nevertheless, all of them admit that the rise of China offers opportunities, and this helps the spread of Mandarin throughout the world. The increasing number of Mandarin learners seem to capitalize on the language. At this point, learning Mandarin is perceived as an advantage because being fluent in Mandarin can increase their competitiveness in global marketplace. That is why in their opinion, people should not spare not efforts in investing in Mandarin.

\section{Linguistic Capital Investment}

Language is more than a means of communication. According to Bourdieu (1991), language has a "symbolic power," and its power depends on the "linguistic market" the language is in. It is through the linguistic market that language is perceived as valuable. Because of that, every speaker of a language "is endowed with linguistic capital, a form of embodied cultural capital defined at the level of the individual" (Zschomler, 2019, p. 2). According to Bourdieu, through the language they speak, speakers 
of a language hold "sign of wealth and authority" because "language is worth what those who speak it are worth" (in Zschomler, 2019, p. 2). Thus, if an individual speaks a certain language deemed prestigious, the individual will have more prestige and credibility. Bourdieu's idea on the symbolic power of a language is helpful in understanding the notion of linguistic investment, namely, language learners spend a lot of efforts in learning a language which they think can help them gain more power in terms of linguistic capital and social skill. In so doing, they try to gain new materials and symbolic assets, and to make use of the capital they already have "as affordances and [transform] this capital into something that is regarded as valuable in new contexts (Darvin \& Norton, 2015, p. 45). Nevertheless, what is considered highly valuable in one place may not possess the same level of value in another place, and what is perceived as valuable can shift. This also happens to language, such as Mandarin.

Nowadays, especially in Asian context, Mandarin has become as important as English to learn. Despite differences in their motivating factors, all my informants agree that Mandarin is worth investing. When asked to explain the importance of learning Mandarin, Lia answers that learning Mandarin would definitely be useful and advantageous for those who learn it. Mandarin can give its learners better opportunities for their career advancement in the future. She also mentions that if Mandarin were not going to be as important as it is now in creating job opportunities, she would not be bothered learning it. She goes on saying that learning Mandarin is not wasting her time and she believes that her investment in Mandarin is beneficial for her future.

Similarly, Ella agrees with Lia. She also considers that Mandarin is worth investing because it can give her business opportunities and enlarge her horizon.

Ella: Now, I think Mandarin is important for work purposes. Because there are many things to do that have something to do with Chinese people. For example, my dad works in a factory so if he wants to buy machinery, it must be from China. And so, to keep the maintenance of the machines, [he] usually calls technicians from China directly. And if you want to have [business] partners, they mostly come from China. So, of course I have to learn [Mandarin]. I also think that it could increase my knowledge.

Ella's context of investment is like Lia's, but not quite similar. Ella's use of the word "knowledge" could refer to a lot of things, including things like cultural awareness and general knowledge. Additionally, Ella explains her point of view, stating that "As long as it is beneficial then I will give it a go. If it is not beneficial, then what is the use for studying it?" Ella's statement emphasizes that learning Mandarin would benefit her, probably in different aspect of her life, including her future.

Both Lia and Ella invest in Mandarin because they understand that they will achieve higher values of their cultural capital and social power, needless to say whether the language would be useful for their future or not. The possibilities are there and that is all that matters to them. And when they in need of it, whether as communication purposes or work purposes or other purposes, the language would be there and ready for them. Lia's and Ella's context is also applicable to other Mandarin learners who believe that their Mandarin language skills is beneficial for them on any future occasion. This is in line with Kurniawan \& Suprajitno's study (2019), which finds that their participants decide to learn Mandarin arguably because of the chances of having better future.

Although Dennis' and Amy's situation is different from that of Lia and Ella - Dennis and Amy teaches Mandarin in a language center, they still spare no efforts in learning Mandarin. They say that they need to improve their Mandarin skills, meaning that they still invest in Mandarin. Dennis tells me upfront that he is forced to be a Mandarin teacher dues to some circumstances. Actually, he is more into business. On the other hand, Amy is quite contented to be a teacher. Yet, she believes that she still needs to improve her Mandarin language skills in order to be a better teacher.

In sum, by investing in Mandarin as linguistic capital, learners just have to observe the market. Kurniawan \& Suprajitno address this claim in their findings as one of "the potential benefits of the mastery of Chinese" $(2019$, p. 5). In the end, "the more markets of domains a linguistic code is used and the more valuable it becomes." (Zhou, 2019, p. 137). The context of the word 'valuable' oftentimes refers to the material potential like a higher salary and more offerings in job opportunities or promotions. In this sense, market domains of Mandarin would be around Asia, slowly climbing its way up to the international English domain market. However, within the globalized landscape, what is considered highly valuable in one place may not possess the same level of value in another place and understanding that difference is not always easy.

\section{Parental Influence}

The last supporting factor which shapes my informants' language ideology is parental influence. According to Dörnyei (1994), enthusiasm level in 
language learning is influenced by several external factors, such as the learning environment, which makes up factors such as students, peer-groups and educational material. Yet social and other factors such as parents and family play a role in influencing the learners' motivation, which is recognized as "parental encouragement" (Wilson, 2012, p. 44). Quoting Gardner, Wilson (2012) suggests that parental influence and control can be divided into two forms of encouragement, that is, active or passive. Parents who have the active type of motivation can determine a positive or negative impact on language learning experience for their children. This positive and negative impact could be seen through their attitudes. If parents facilitate and give reward for their children, then it is viewed as positive impact, whereas the negative impact would be presented by the parents who display their negative attitudes towards the group or the individuals and even oppose L2 learning. Nevertheless, parents with passive roles support the willingness of their children to communicate with the language speakers through their behavior towards the L2 group ( $\mathrm{Ng} \& \mathrm{Ng}, 2015)$.

Gardner (2010) acknowledges that the children's awareness toward the benefit in learning a language could be seen through the parents' attitude. And this is exactly the case with my young Chinese Surabayanese informants. To begin with, one of my young Chinese Surabayanese informants' criteria is to highlight the fact that they were told to take Mandarin courses by their parents. Lia, Ella, Amy, and Dennis were all introduced to Mandarin by their parents. Later one, they continued to learn Mandarin because it was a subject taught in their schools. Oskamp (in Chambers, 1999 , p. 45) writes that parental influence is at its strongest in the early years of a language learner. Consequently, all of my young Chinese Surabayanese informants were introduced to Mandarin since they were little. My informants also reported how their parents would attempt to converse in Mandarin on daily occasions. For Lia and Dennis, it was their mother who pushed them to practice their Mandarin skill. Meanwhile, for Ella and Amy, it was their father who encouraged them to practice Mandarin in daily conversation. Within the cases of my informants, this proved how effective parental roles are.

According to Chang \& Sandhofer (2019), language input was proven to be an important source of informal learning for young children prior to formal schooling. A strong relationship between infant vocabulary development and the total number of parental languages spoken to children during daily activities has been observed. This shows how effective parental roles when were encouraged to practice their
Mandarin in daily conversations. All of my informants say that they learnt Mandarin when they were still kids because their parents told them to do so. They would not have learned Mandarin if their parents had not told them to do so. For example, in Amy's case, she has always been encouraged to learn Mandarin by her grandfather since she was little.

Amy: [Yes, [learning Mandarin] helped me to confirm, that was for sure. If you cannot speak Mandarin, then you are not Chinese. Or perhaps, this could also because my grandfather always told me that since I was little, so it's like-]

In Lia's case, her parents told her to learn Mandarin. Lia did it when she was told to do so. Her motivation was to obey her parents. Her interest grew, in line with the increasing personal use of Mandarin within the family's daily conversation, and she felt that she was challenged when her course materials were getting more and more difficult. The more she knows Mandarin and the more she learns about it, the more she believes that Mandarin is going to be useful for her in the future or in her life, as she likes to put it "if it is not for business, then for communication". Lia experiences a change in motivation that is not fully controlled by her parents but by external influences that she is exposed to, even though her motivation changed in a sense of increasing and decreasing, she keeps her motivation as instrumental, from her point of view.

Ella's situation is similar to Lia's. At first she learned Mandarin because she wanted to obey her parents. However, as she grew older, she experienced ups and downs in learning Mandarin. When the course materials were easy, it was fun for her to learn Mandarin. However, when the materials were getting more and more difficult, the fun was gone, and her motivation weakened. In addition, Ella is aware that mastering Mandarin is never on the top of her priority list and there are other more important things to be taken care of. In this case, Ella's motivation decreased. Nevertheless, Ella keeps on learning Mandarin, and the ups and downs in learning Mandarin do not change her instrumental motivational status.

In Dennis' case, his motivation is steady. At first, he was told to learn Mandarin in order to communicate, to keep in touch with his relatives in China. His mother was very supportive. She creates an environment of learning Mandarin by pushing him to participate in the family's Mandarin conversation in order to increase his Mandarin skill. He admitted that he was not motivated to learn Mandarin. He learned it because he had to. There were times when he was being a bad student in learning Mandarin and had to repeat the 
same level because of the increased difficulty of course work and prioritizing other important matters. Obviously, this resulted in decreasing motivation. But then, when he started to understand how Mandarin was beneficial for his life and for his future, his motivation increases little by little. His motivation then grows stronger in order to improve his Mandarin skill for travel and business. So, in a similar manner with Ella, business is always at the top in his priority list but not Mandarin. The ups and downs in his motivation do not result Dennis' motivation to shift to any other than instrumental as he experienced the benefit of Mandarin, "Learning Mandarin is surely difficult, but the benefit is amazing."

To sum up, all of my informants perceive their parents to be a positive influence. My informants' parents have positive attitudes toward Mandarin, and they encourage their children to learning the language. The parental encouragement pushes Lia, Ella, Amy, and Dennis to be active participants and active learners in a daily conversational context. The positive encouragement and the establishment of a supportive environment for learning Mandarin give advantages to my informants. They are able to practice their Mandarin in a conducive and supporting environment. This parental influence constructs their motivation to learn Mandarin. And due to China's political and economic power, Mandarin is perceived to give advantages to its speakers.

\section{CONCLUSION}

This study aims at exploring the ideology within young Chinese Surabayanese's decision in learning Mandarin. The finding reveals one major ideology, namely, learning Mandarin is perceived as an advantage by Mandarin learners. This ideology is supported by four factors, which influence my informants' decision to learn Mandarin. Those factors are globalizing their life opportunities, the rise of China, linguistic capital investment, and lastly, parental influence.

My informants believe that learning Mandarin helps them go global with their life opportunities. Mandarin learners are mainly encouraged to learn Mandarin because of the opportunities in job market. The opportunities in job market is seen as the result of the rise of China. While only one informant explicitly mentions that the rise of China influences her decision to learn Mandarin, the rest of the informants mentions that China's economic power encourages them to learn Mandarin. Thus, implicitly they acknowledge that the rise of China also contributes to their motivation to learn the language. This second factor leads to the third one. Instead of thinking that investing in Mandarin is a waste of time, all my informants agree that investing in Mandarin offers better opportunities in the future. Investing in Mandarin is not merely about business but also relate to communication and cultural exchanges in this globalized world. Lastly, parental influence plays an important role in encouraging my informants to learn Mandarin. They provide supportive and conducive environments for learning the language. These four factors construct my informants' ideology in learning Mandarin, namely, Mandarin is thought to give its learners advantages.

\section{REFERENCES}

Bewley, F. (2018). Culture and language ideology in Chinese foreign language textbooks: A thematic analysis (Unpublished master's thesis). University of British Columbia, Vancouver, Canada.

Bianco, J. L. (2007). Emergent China and Chinese: Language planning categories. Language Policy, 6(1), pp. 3-26. doi: 10.1007/s10993-006-9042-3.

Bourdieu, P. (1991). Language and symbolic power. J. B. Thompson et. Al., trans. Cambridge, MA: Harvard University Press.

Chambers, G. N. (1999). Motivating language learners. Clevedon, UK: Multilingual Matters.

Chang, A., \& Sandhofer, C. M. (2019). How bilingual parents talk to children about number in Mandarin and English. Frontiers in Psychology, 10, pp. 1-11. doi: 10.3389/fpsyg.2019.01090.

Cook, V. (2008). Second language learning and language teaching. 4th Ed. London: Edward Arnold.

Cummins, J. (2006). Identity texts: The imaginative construction of self through multiliteracies pedagogy. In O. García, T Skutnabb-Kangas, \& M. E. Torres-Guzmán, (Eds), Imagining multilingual schools: Languages in education and glocalization (pp. 51-68). Clevedon, UK: Multilingual Matters.

Darvin, R. \& Norton, B. (2015). Identity and a model of investment in applied linguistics. Annual Review of Applied Linguistics, 35, pp. 36-56. doi: 10.1017/S0267190514000191.

Ding, S. \& Saunders, R. A. (2006). Talking up China: An analysis of China's rising cultural power and global promotion of the Chinese language. East Asia, 23(2), pp. 3-33. doi: 10.1007/s12140-0060021-2.

Dhir, K. (2005). The value of language: concept, perspectives, and policies. Corporate Communications: An International Journal, 10(4), 358-382. doi: 10.1108/13563280510630151.

Dörnyei, Z. (1994). Motivation and motivating in the foreign language classroom. The Modern Language Journal, 78(3), pp. 273-284. doi: 10.2307/330107. 
Dörnyei, Z., Csizér, K, \& Németh, N. (2006). Motivation, language attitudes and globalisation: A Hungarian perspective. Clevedon, UK: Multilingual Matters.

Dörnyei, Z., \& Ushioda, E. (2009). Motivation, language identity and the L2 self. Bristol, UK: Multilingual Matters.

Gardner, R. C. (1985). Social psychology and second language learning: The roles of attitudes and motivation. London: Edward Arnold.

Gardner, R. C. (2010). Motivation and second language acquisition: The socio-educational model. New York, NY: Peter Lang Publishing.

Goh, Y. S. \& Lim, S. L. (2010). Global Mandarin. In V. Vaish, (Ed.), Globalization of language and culture in Asia: The impact of globalization processes on language (pp. 14-33). New York: Continuum.

Hau, C. S. (2012). Becoming "Chinese" - But what "Chinese"? - in Southeast Asia. The Asia-Pacific Journal: Japan Focus, 10(26), no. 2, pp. 1-37. Retrieved from https://apjjf.org/-Caroline-S-Hau/3777/article.pdf.

He, A. W. (2006). Toward an Identity Theory of the Development of Chinese as a Heritage Language. Heritage Language Journal, 4(1), pp. 1-28.

Hui, F. (2007). The changing language ideology and linguistic market in the globalization of China. Caligrama (São Paulo. Online), 3(2), pp. 1-13. doi: 10.11606/issn.1808-0820.cali.2007.65466.

Kurniawan, B. \& Suprajitno, S. (2019). Chinese as a Cultural Capital: The Case Study of Chinese Heritage Language Learners. $k @ t a, 21(1)$, pp. 19. doi: 10.9744/kata.21.1.1-9.

Lee, R. E. (2006). Globalization, language, and culture. New York: Chelsea House.

Mu, G. M. (2016). Learning Chinese as a heritage language: An Australian perspective. Bristol, UK: Multilingual Matters.

Murray, G., Gao, X., \& Lamb, T. (2011). Identity, motivation and autonomy. Bristol, UK: Multilingual Matters.
Ng, C. F., \& Ng, P. K. (2015). A review of intrinsic and extrinsic motivations of ESL learners. International Journal of Languages, Literature and Linguistics, 1(2), pp. 98-105. doi: 10.7763/ IJLLL.2015.V1.20.

Norton, B. (2013). Identity and language learning: Extending the conversation. 2nd Ed. Bristol, UK: Multilingual Matters.

Salmon, C. (2009). The Chinese community of Surabaya, from its origins to the 1930s crisis. Chinese Southern Diaspora Studies, 3, pp. 22-60.

Setijadi, C. (2015). Being Chinese again: Learning Mandarin in Post-Suharto Indonesia. In W. Li, (Ed.), Multilingualism in the Chinese diaspora worldwide (pp. 141-157). New York: Routledge.

Suprajitno, S. (2019). Various petals of the lotus: The identities of the Chinese Buddhists in Indonesia. Archiv Orientální, 87(2), 333-358.

Wen, X. (2011). Chinese language learning motivation: A comparative study of heritage and nonheritage learners. Heritage Language Journal, 8(3), pp. 41-66.

Wilson, A. E. (2012). Interpreting differences in parental encouragement to learn the host language: California and Catalonia compared. Bellaterra: Journal of Teaching and Learning Language and Literature, 5(3), pp. 4456. doi: $10.5565 / \mathrm{rev} / \mathrm{jt13.469.}$

Woolard, K. A. (1998). Introduction: Language ideology as a field of inquiry. In B. B. Schieffelin, K. A. Woolard, \& P. V. Kroskrity, (Eds), Language ideologies: Practice and theory (pp. 347). New York: Oxford University Press.

Yin, R. K. (2011). Qualitative Research from Start to Finish. New York, NY: The Guilford Press.

Zhou, M. (2019). Language ideology and order in rising China. Singapore: Palgrave Macmillan.

Zschomler, S. (2019). 'Language Is Your Dignity': Migration, Linguistic Capital, and the Experience of Re/De-Valuation. Languages, 4(64), pp. 1-14. doi: 10.3390/languages4030064. 